\title{
Asthma at 8 years of age in children born by caesarean section
}

\author{
C Roduit, ${ }^{1}$ S Scholtens, ${ }^{2} \mathrm{~J}$ C de Jongste, ${ }^{3}$ A H Wijga, ${ }^{1} \mathrm{~J} \mathrm{Gerritsen,}{ }^{4}$ D S Postma, ${ }^{4}$ \\ B Brunekreef, ${ }^{2,5}$ M 0 Hoekstra, ${ }^{6}$ R Aalberse, ${ }^{7,8}$ H A Smit ${ }^{1,5}$
}

${ }^{1}$ Centre for Prevention and Health Services Research, National Institute for Public Health and the Environment, Bilthoven, The Netherlands;

${ }^{2}$ Institute for Risk Assessment Sciences, Utrecht University,

Utrecht, The Netherlands;

${ }^{3}$ Department of Pediatrics,

Division of Respiratory Medicine,

Erasmus MC - Sophia,

Rotterdam, The Netherlands;

${ }^{4}$ Beatrix Children's Hospital,

University Medical Centre

Groningen, University of

Groningen, Groningen, The

Netherlands; ${ }^{5}$ Julius Center for

Health Sciences and Primary

Care, University Medical Center

Utrecht, Utrecht, The

Netherlands; ${ }^{6}$ Centre for

Paediatric Allergology,

Wilhelmina Children's Hospital,

Utrecht, The Netherlands;

${ }^{7}$ Sanquin Research,

Amsterdam, The Netherlands;

${ }^{8}$ Landsteiner Laboratory,

Academic Medical Centre,

University of Amsterdam,

Amsterdam, The Netherlands

Correspondence to:

Dr H A Smit, National Institute for Public Health and the

Environment (RIVM), Centre for

Prevention and Health Services

Research (pb 101), P 0 Box 1,

3720 BA Bilthoven, The

Netherlands; jet.smit@rivm.nl

Received 25 April 2008

Accepted 7 September 2008

Published Online First

3 December 2008

\begin{abstract}
Background: Caesarean section might be a risk factor for asthma because of delayed microbial colonisation, but the association remains controversial. A study was undertaken to investigate prospectively whether children born by caesarean section are more at risk of having asthma in childhood and sensitisation at the age of 8 years, taking into account the allergic status of the parents.
\end{abstract}

Methods: 2917 children who participated in a birth cohort study were followed for 8 years. The definition of asthma included wheeze, dyspnoea and prescription of inhaled steroids. In a subgroup ( $n=1454)$, serum lgE antibodies for inhalant and food allergens were measured at 8 years.

Results: In the total study population, $12.4 \%(n=362)$ of the children had asthma at the age of 8 years. Caesarean section, with a total prevalence of $8.5 \%$, was associated with an increased risk of asthma (OR 1.79; $95 \% \mathrm{Cl} 1.27$ to 2.51). This association was stronger among predisposed children (with two allergic parents: OR 2.91; $95 \% \mathrm{Cl} 1.20$ to 7.05 ; with only one: OR 1.86; $95 \% \mathrm{Cl} 1.12$ to 3.09$)$ than in children with non-allergic parents (OR 1.36; $95 \% \mathrm{Cl} 0.77$ to 2.42). The association between caesarean section and sensitisation the age of 8 years was significant only in children of non-allergic parents (OR 2.14; 95\% Cl 1.16 to 3.98).

Conclusions: Children born by caesarean section have a higher risk of asthma than those born by vaginal delivery, particularly children of allergic parents. Caesarean section increases the risk for sensitisation to common allergens in children with non-allergic parents only.

Caesarean section may have contributed to the rise in asthma. The mode of delivery has been reported to influence the development of allergic diseases in childhood. ${ }^{2}$ The prevalence of allergies and asthma in childhood has increased dramatically over the past few decades, mostly in industrialised countries. ${ }^{3}$ In parallel, rates of caesarean delivery have risen in most of the developed countries, from about $5 \%$ in the 1970 s to over $30 \%$ in 2000 in some regions of the world..$^{5-7}$ The Netherlands still has a low rate of caesarean section compared with other western countries owing to practices of the maternity care system. ${ }^{8}$

The hygiene hypothesis states that a decreased exposure to microorganisms early in life leads to an insufficient stimulation of the Th1 lymphocytes and therefore a predominance of the Th2 allergic response. ${ }^{9}$ The initial microbial exposure for children born by caesarean section is delayed compared with those born by vaginal delivery. ${ }^{10}$ Moreover, the intestinal flora has been shown to be different in these children. ${ }^{11}$ The maturation of the immune systems might therefore be different and may be delayed in children born by caesarean section. ${ }^{12}$

The association between mode of delivery and asthma remains controversial. Although some researchers observed an increased risk for development of asthma among children born by caesarean section compared with children born by vaginal delivery, ${ }^{13-18}$ others found no such relationship. ${ }^{19-23}$ However, the studies differ considerably in the methods, length of follow-up and the definition of asthma, which could explain the inconsistent results. A recent meta-analysis found a $20 \%$ increased risk of asthma in children born by caesarean section. ${ }^{24}$ However, only a few studies have taken account of the genetic predisposition for allergy when examining the association between caesarean section and asthma. Admittedly, parental history of allergy is a strong risk factor for asthma in childhood and the interaction between genes and environment might be important in the development of this disease. ${ }^{25} 26$ Eggesbo et al reported a significantly increased risk for food allergy in children of allergic mothers born by caesarean section, but this association was not significant in children of nonallergic mothers. ${ }^{2}$

We have examined the association between delivery by caesarean section and asthma and allergic sensitisation at the age of 8 years in a prospective birth cohort, the Prevention and Incidence of Asthma and Mite Allergy (PIAMA) study. In addition, we assessed the cumulative incidences of asthma from ages 3-8 years in children born by caesarean section compared with those born by vaginal delivery. To evaluate the influence of the parental history of allergy on this association, we stratified our analyses according to parental allergic status.

\section{METHODS \\ Study design}

In the PIAMA study, mothers were recruited during pregnancy from the general population in three regions of the Netherlands using a validated screening questionnaire. A detailed description of this study has been published elsewhere. ${ }^{27}$ Briefly, based on the screening, 7862 women (2779 allergic and 5083 non-allergic) were invited to participate in the study and 4146 women (53\%) agreed (1327 allergic and 2819 non-allergic). Their children were followed up for 8 years.

At the start of the study, all children with an allergic mother $(n=1327)$ and a random sample of 
the children with a non-allergic mother $(n=663)$ were selected for close follow-up including blood tests to determine the level of specific IgE to common allergens. Standardised questionnaires were sent to all participating parents 2 months before delivery, at the age of 3 months and annually starting when the child was 1 year old.

The study protocol was approved by the medical ethics committees of the participating institutes and all parents gave written informed consent.

\section{Study population}

At baseline the PIAMA study population consisted of 4146 children born between May 1996 and December 1997. Twins were excluded from the analysis $(n=39)$ and 489 children were lost to follow-up by the age of 8 years. The 8 -year questionnaire was returned for 3238 children (89.5\% of sent questionnaires). After exclusion of children with missing data on asthma at the age of 8 years $(n=41)$, on mode of delivery $(n=35)$, parental history of allergy or on potential confounders $(n=245)$, data for 2917 children were available for analysis.

At the age of 8 years, data on specific IgE were available for 1703 children. After exclusion of children with missing data on asthma, mode of delivery and potential confounders, 1454 children were available for analysis of specific IgE.

\section{Definitions}

Every year, parents reported information on symptoms and treatment of asthma and on doctor-diagnosed asthma. Children were labelled as having asthma if they had one or more attacks of wheeze in the previous 12 months and/or one or more events of dyspnoea in the previous 12 months and/or prescription of inhaled steroids by a doctor for respiratory or lung problems in the previous 12 months. Chronic asthma was defined as asthma at any age between 3 and 7 years in combination with asthma at the age of 8 years.

Data on the mode of delivery, gender, birth weight, gestational age, Apgar score, breastfeeding, presence of siblings and on maternal age, weight, height, education and smoking during pregnancy were obtained from the self-reported questionnaires completed during the third trimester of pregnancy, 3 months after birth and at 1 year of age. Maternal and paternal allergy was defined as current allergy to house dust mite or pets, current hay fever or ever asthma; this information was self-reported. Breastfeeding was defined as any kind of breastfeeding, including

Table 1 Characteristics of the study population

\begin{tabular}{|c|c|c|c|}
\hline & $\begin{array}{l}\text { Total } \\
\% \text { (N) }\end{array}$ & $\begin{array}{l}\text { Vaginal delivery } \\
\% \text { (N) }\end{array}$ & $\begin{array}{l}\text { Caesarean section } \\
\% \text { (N) }\end{array}$ \\
\hline All & $100(2917)$ & $91.5(2670)$ & $8.5(247)$ \\
\hline \multicolumn{4}{|l|}{ Gender } \\
\hline Girls & $48.8(1425)$ & $49.4(1318)$ & $43.3(107)$ \\
\hline \multicolumn{4}{|l|}{ Birth weight } \\
\hline$<2500 \mathrm{~g}$ & $2.8(80)$ & $2.0(53)$ & $10.9(27)$ \\
\hline $2500-4500 \mathrm{~g}$ & 93.7 (2734) & $94.8(2531)$ & $82.2(203)$ \\
\hline$>4500 \mathrm{~g}$ & $3.5(103)$ & $3.2(86)$ & $6.9(17)$ \\
\hline \multicolumn{4}{|c|}{ Gestational age (weeks) } \\
\hline$<32$ & $0.3(8)$ & $0.1(3)$ & $2.0(5)$ \\
\hline $32-36$ & $4.1(118)$ & $3.8(100)$ & $7.3(18)$ \\
\hline $37-41$ & $74.2(2164)$ & $75.2(2006)$ & $64.0(158)$ \\
\hline$>41$ & $21.4(625)$ & 20.9 (559) & $26.7(66)$ \\
\hline \multicolumn{4}{|c|}{ Intrauterine growth restriction } \\
\hline$<10$ th percentile & $0.9(27)$ & $0.6(16)$ & $4.4(11)$ \\
\hline \multicolumn{4}{|c|}{ Number of respiratory infections in the first year } \\
\hline 0 & $49.2(1426)$ & $49.2(1304)$ & 49.4 (122) \\
\hline $1-2$ & $37.4(1084)$ & $37.4(990)$ & $38.1(94)$ \\
\hline$\geqslant 3$ & $13.4(386)$ & $13.4(355)$ & $12.5(31)$ \\
\hline \multicolumn{4}{|l|}{ Maternal education } \\
\hline Low & 20.7 (605) & $20.3(542)$ & $25.5(63)$ \\
\hline Intermediate & $41.7(1215)$ & $41.9(1120)$ & $38.5(95)$ \\
\hline High & $37.6(1097)$ & $37.7(1008)$ & $36.0(89)$ \\
\hline \multicolumn{4}{|l|}{ Mother's job } \\
\hline Employed & $63.0(1832)$ & $62.6(1668)$ & $66.7(164)$ \\
\hline Self-employed & $4.8(141)$ & $4.6(122)$ & $7.7(19)$ \\
\hline Housewife & $26.8(779)$ & $27.3(727)$ & $21.1(52)$ \\
\hline Unemployed & $5.4(157)$ & $5.5(146)$ & $4.4(11)$ \\
\hline \multicolumn{4}{|c|}{ Maternal smoking during pregnancy } \\
\hline Yes & $11.9(348)$ & $12.0(319)$ & $11.7(29)$ \\
\hline \multicolumn{4}{|l|}{ No of older siblings } \\
\hline 0 & $50.0(1455)$ & $48.8(1273)$ & $73.7(182)$ \\
\hline 1 & $35.8(1041)$ & $37.0(984)$ & $23.1(57)$ \\
\hline$\geqslant 2$ & $14.2(412)$ & $15.2(404)$ & $3.2(8)$ \\
\hline \multicolumn{4}{|l|}{ Parents with allergy } \\
\hline 0 & $51.3(1495)$ & $51.4(1371)$ & $50.2(124)$ \\
\hline 1 & $39.6(1156)$ & $39.6(1058)$ & $39.7(98)$ \\
\hline 2 & $9.1(266)$ & $9.0(241)$ & $10.1(25)$ \\
\hline
\end{tabular}


Table 2 Prevalence of respiratory outcomes $(n=2917)$ and specific $\lg E(n=1454)$ at the age of 8 years

\begin{tabular}{|c|c|c|c|c|}
\hline & $\begin{array}{l}\text { Total } \\
\% \text { (N) }\end{array}$ & $\begin{array}{l}\text { Non-allergic } \\
\text { parents } \\
\% \text { (N) }\end{array}$ & $\begin{array}{l}\text { Only one allergic } \\
\text { parent } \\
\% \text { (N) }\end{array}$ & $\begin{array}{l}\text { Two allergic } \\
\text { parents } \\
\% \text { (N) }\end{array}$ \\
\hline \multicolumn{5}{|c|}{ Asthma at the age of 8} \\
\hline Yes & $12.4(362)$ & $8.8(131)$ & $14.9(172)$ & $22.2(59)$ \\
\hline No & $87.6(2555)$ & $91.2(1364)$ & 85.1 (984) & $77.8(207)$ \\
\hline \multicolumn{5}{|c|}{$\begin{array}{l}\text { Wheeze ( } \geqslant 1 \text { episode in } \\
\text { previous } 12 \text { months) }\end{array}$} \\
\hline Yes & $6.2(182)$ & $4.1(61)$ & $7.9(91)$ & $11.3(30)$ \\
\hline No & $93.8(2735)$ & $95.9(1434)$ & $92.1(1065)$ & $88.7(236)$ \\
\hline \multicolumn{5}{|c|}{$\begin{array}{l}\text { Dyspnoea ( } \geqslant 1 \text { episode in } \\
\text { previous } 12 \text { months) }\end{array}$} \\
\hline Yes & $8.4(246)$ & $6.0(89)$ & $9.9(114)$ & $16.2(43)$ \\
\hline No & $91.6(2671)$ & $94.0(1406)$ & $90.1(1042)$ & $83.8(223)$ \\
\hline \multicolumn{5}{|c|}{$\begin{array}{l}\text { Prescription of inhaled steroid } \\
\text { (in previous } 12 \text { months) }\end{array}$} \\
\hline Yes & $6.3(184)$ & $4.6(68)$ & $7.6(88)$ & $10.5(28)$ \\
\hline No & $93.7(2733)$ & $95.4(1427)$ & $92.4(1068)$ & $89.5(238)$ \\
\hline \multicolumn{5}{|c|}{ Any specific IgE positive } \\
\hline Yes & 40.9 (595) & $34.6(225)$ & 44.1 (279) & $53.5(91)$ \\
\hline No & 59.1 (859) & $65.4(426)$ & $55.9(354)$ & $46.5(79)$ \\
\hline
\end{tabular}

partial breastfeeding and categorised as no breastfeeding, 0 12 weeks of breastfeeding and $>12$ weeks of breastfeeding. The educational level of the mother was measured as the highest education completed and then divided into three categories (low, intermediate, high). Maternal body mass index (BMI) was calculated from reported body weight and height when the child was 1 year old.

In the subgroup of children with a close follow-up, specific IgE to inhalant (house dust mite, grass, birch, Alternaria alternata, cat and dog) and food allergens (milk or eggs) was determined by means of RAST at the age of 8 years. Sensitisation to a specific allergen was defined as a specific IgE concentration of $>0.35 \mathrm{IU} / \mathrm{ml}$ to at least one of the allergens.

\section{Statistical analysis}

Data analysis was conducted using SAS software Version 9.1 (SAS Institute, Cary, North Carolina, USA). Multiple logistic regression analysis was used to study the association between caesarean section and asthma and specific sensitisation at the age of 8 years. Estimates of cumulative incidence of chronic asthma from the ages of 3-8 years were calculated by the Kaplan-Meier method. The differences between the two strata

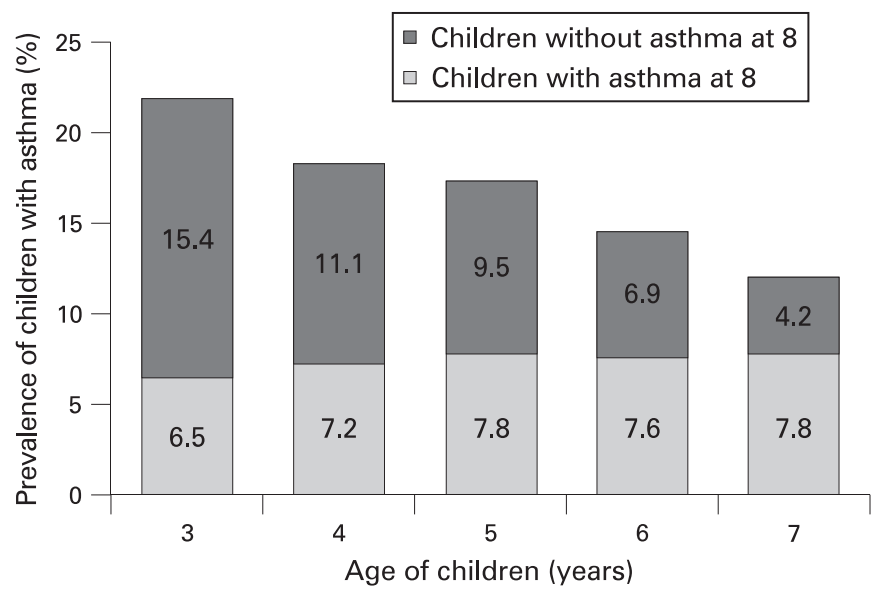

Figure 1 Prevalence of asthma at 3-7 years of age. (caesarean section versus no caesarean section) were assessed using the log rank test. The Cox proportional hazard model was used to analyse the relation between caesarean section and chronic asthma. Adjustment was made for the following potential confounders: gender, birth weight, maternal education, breastfeeding, maternal BMI and parental allergy. Gestational age was not included in the model because of the strong association with birth weight and analyses restricted among children born at term showed similar results. Mother's age, number of siblings, intrauterine growth restriction, Apgar score, breathing problems after delivery and the number of respiratory infections in the first year of life were added to the model but did not change the results so they were not kept in the final model. Analyses were performed for the total study population and separately for children: (1) with non-allergic parents, (2) with only one allergic parent and (3) with two allergic parents. The numbers in the individual strata were small and the results showed no significant interactions. To improve power, an interaction variable with four categories based on parental allergic status and caesarean section was entered into the logistic model. A p value of $<0.05$ was considered to be statistically significant.

\section{RESULTS}

\section{General characteristics}

In the total study population, 247 of the 2917 children (8.5\%) were born by caesarean section (table 1$)$. The proportion of the children with non-allergic parents was $51.3 \%$ ( $\mathrm{n}=1495)$, with only one allergic parent $39.6 \%(n=1156)$ and with two allergic parents $9.1 \%(n=266)$; there was no differences between children born by vaginal delivery and those born by caesarean section. Among children born by caesarean section, the frequency of low birth weight, as well as prematurity, intrauterine growth restriction and low number of siblings was higher than for those born by vaginal delivery. For the other characteristics, there were no differences depending on the mode of delivery.

The children excluded from the analysis because of loss to followup $(n=489)$, non-response to the 8-year questionnaire $(n=380)$ and missing data $(n=321)$ differed slightly from the children who were included ( $n=2917$ ). Compared with the included children, those excluded were more likely to have an allergic mother, to have a mother with lower education and a mother who smoked during 


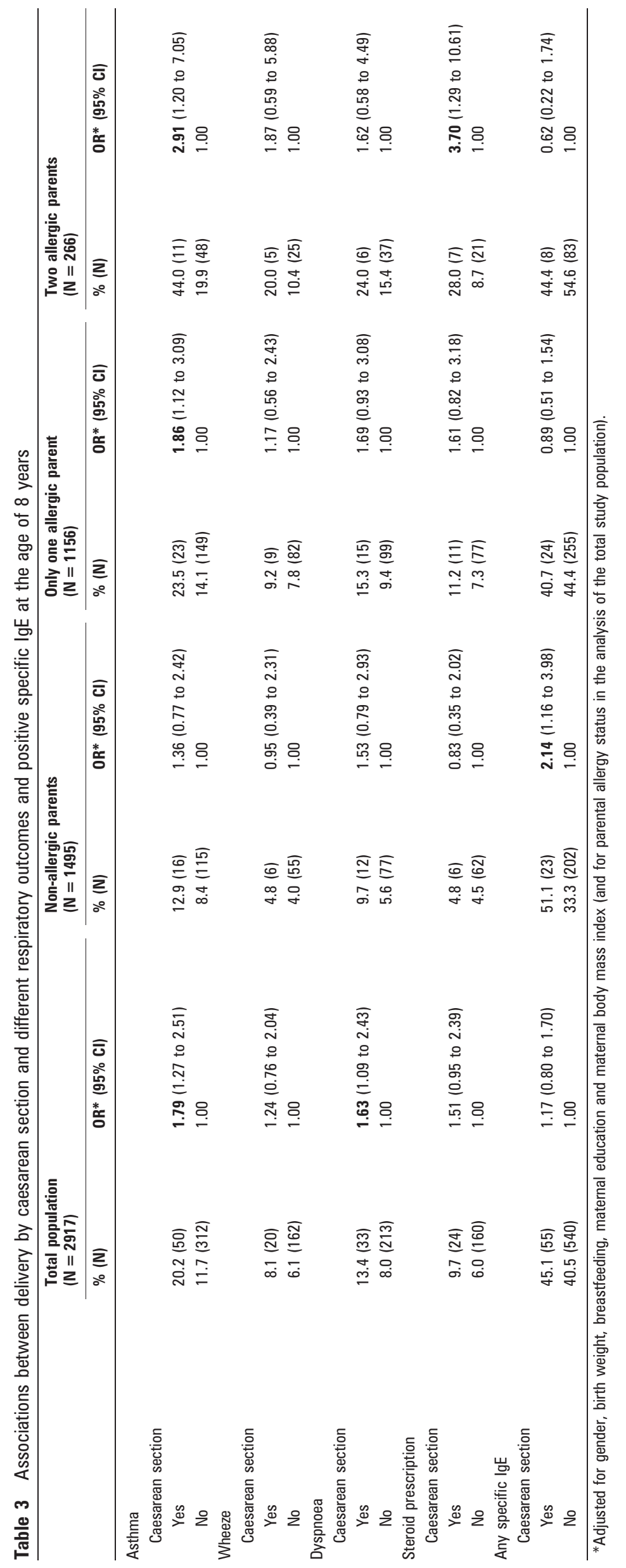




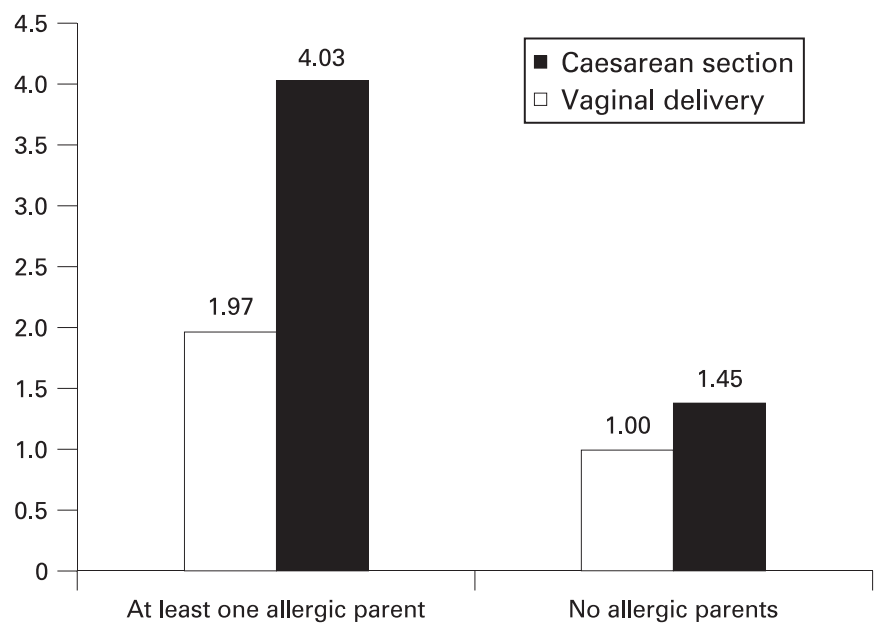

Figure 2 Adjusted odds ratio (OR) for asthma at 8 years in relation to mode of delivery, stratified for parental history of allergy.

pregnancy (data not shown). The prevalence of children born by caesarean section was similar for the children included and those excluded ( $8.5 \%$ and $8.4 \%$, respectively).

\section{Prevalence of respiratory outcomes}

The overall prevalence of asthma was $12.4 \%(n=362)$ at the age of 8 years (table 2). The prevalence was higher among children with only one allergic parent (14.9\%) or two allergic parents $(22.2 \%)$ than among children with non-allergic parents (8.8\%). A similar trend was observed in the prevalence of wheeze, dyspnoea and prescription of steroid. The prevalence of asthma showed a decline from the ages of 3 to 7 years (from 21.9\% to 12.0\%); however, the proportion of children with chronic asthma-defined as asthma at any age between 3 and 7 years in combination with asthma at 8 years of age - was stable over time (fig 1 ). This means that most of the children with asthma persisting until 8 years of age already had symptoms at the age of 3 years.

\section{Prevalence of children with sensitisation}

Allergic sensitisation to at least one common allergen (inhalant or food) at the age of 8 years was common in the total study population (40.9\%, table 2 ). The percentage of children with sensitisation to any specific allergen was higher in children with two allergic parents than in children of non-allergic parents (53.5\% and $34.6 \%$, respectively). The same tendencies were observed for inhalant and food allergens (data not shown).

\section{Association between caesarean section and respiratory outcomes}

In the total study population, children born by caesarean section had a higher risk of asthma at the age of 8 years in both the crude and adjusted analysis (OR 1.79; 95\% CI 1.27 to 2.51 ; table 3). Associations in a similar direction were observed between caesarean section and individual symptoms (wheeze, dyspnoea and prescription of inhaled steroids). The risk of having asthma in children born by caesarean section was increased by almost twofold in children with only one allergic parent and by threefold in those with two allergic parents (OR 1.86; $95 \%$ CI 1.12 to 3.09 and OR 2.91; 95\% CI 1.20 to 7.05 , respectively). Both maternal and paternal allergy had a similar influence on this association, but maternal allergy had a stronger effect than paternal allergy (OR 2.13; 95\% CI 1.10 to 4.15 and OR 1.54 ; $95 \%$ CI 0.68 to 3.49 , respectively; data not shown). The association between caesarean section and asthma in children of non-allergic parents had a similar trend but was not statistically significant (OR 1.36 ; $95 \%$ CI 0.77 to 2.42 ). The analysis of doctor-diagnosed asthma as the outcome at the age of 8 years showed the same tendency as the association with caesarean section (data not shown).

In order to evaluate the effect modification by parental allergic status in the whole study population, we used a variable with four categories: children with at least one allergic parent or not and born by caesarean section or not. A strong association was observed between children with at least one allergic parent and born by caesarean section and the outcome (asthma at 8 years) compared with the reference group (children not predisposed and born by vaginal delivery: OR 4.03; 95\% CI 2.58 to 6.27; fig 2). Among children with non-allergic parents, those born by caesarean section had a 1.5-fold increased risk of having asthma and, among predisposed children (with at least one allergic parent), the risk of having asthma increased fourfold.

From 3 to 8 years of age, children born by caesarean section had an increased risk of chronic asthma compared with those born by vaginal delivery (hazard ratio 1.77; 95\% CI 1.29 to 2.43 ). A similar trend, as in the cross-sectional analysis at 8 years of age, was observed with children with chronic asthma and different parental allergic status (table 4). At the age of 8 years, the cumulative incidence of chronic asthma in the total population was $17.1 \%$ in children born by caesarean section and $9.8 \%$ in those born by vaginal delivery (fig 3). The difference in the cumulative incidences between these two groups was constant over time, but among children with allergic parents this difference was more important.

\section{Association between caesarean section and specific sensitisation}

Children with non-allergic parents born by caesarean section had a higher risk of sensitisation to any specific allergen at the age of 8 years (OR 2.14; 95\% CI 1.16 to 3.98, table 3). In children with one or two allergic parents, caesarean section was not associated with specific sensitisation. The association, analysed separately for sensitisation to inhalant or food allergens, was not significant and difficult to interpret because of very small numbers in each

Table 4 Associations between caesarean section and chronic asthma from the ages of 3 to 8 years

\begin{tabular}{llllc}
\hline & $\begin{array}{l}\text { Number of events } \\
\text { (chronic asthma) }\end{array}$ & HR & Adjusted* HR (95\% CI) & p Value \\
\hline All & $11.1(348)$ & 1.89 & $1.77(1.29$ to 2.43) & $<0.001$ \\
Non-allergic parents & $8.3(124)$ & 1.54 & $1.30(0.74$ to 2.28) & 0.36 \\
Only one allergic parent & $14.5(168)$ & 1.87 & $1.81(1.14$ to 2.88) & 0.01 \\
Two allergic parents & $21.1(56)$ & 3.01 & $2.72(1.28$ to 5.78) & 0.01 \\
\hline
\end{tabular}

\footnotetext{
The hazard ratio (HR) is for the children born by caesarean section compared with children born by vaginal delivery.

${ }^{*}$ Adjusted for gender, birth weight, breastfeeding, maternal education and maternal body mass index (and for parental allergy status in the analysis of the total study population).
} 

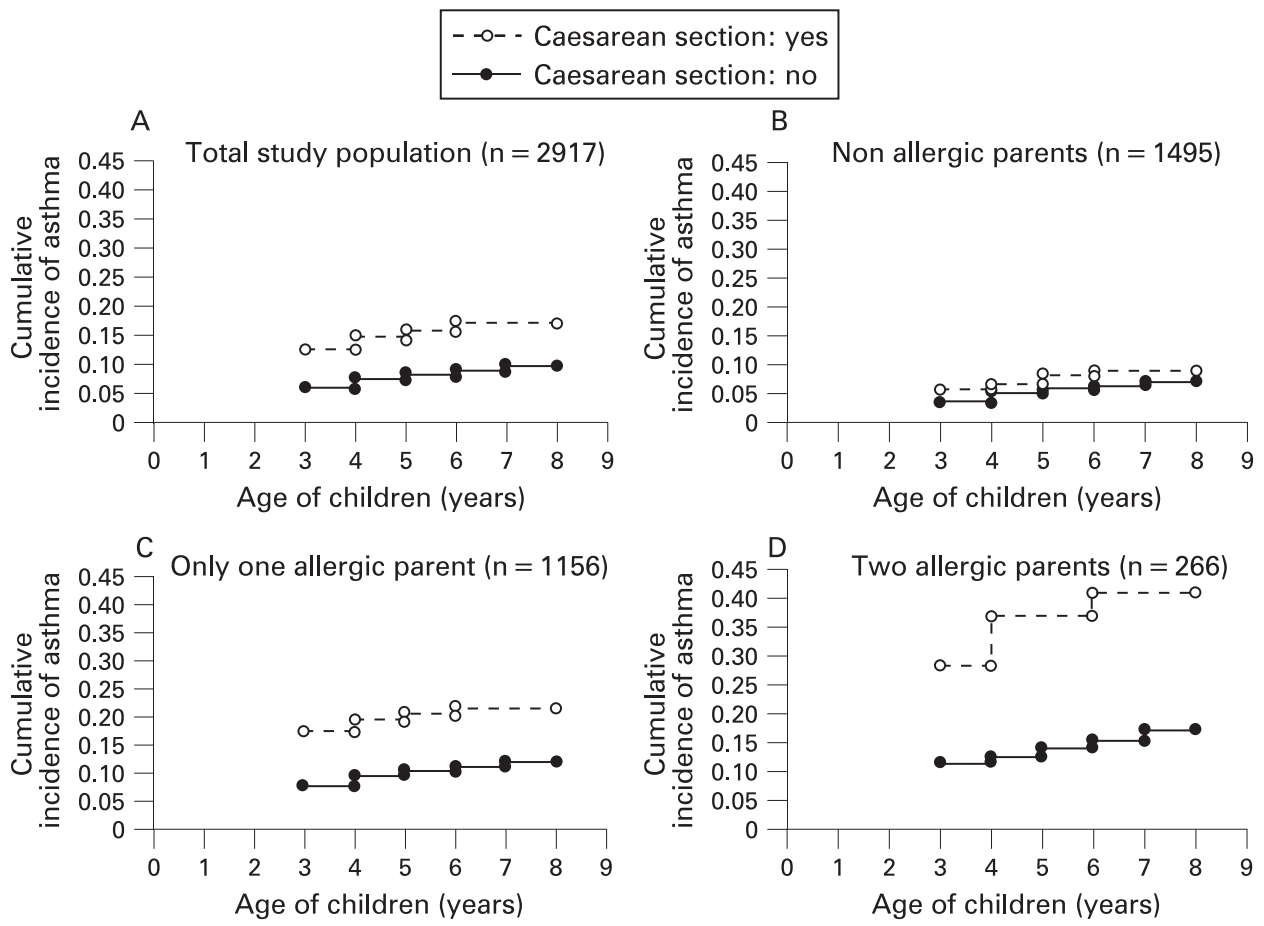

Figure 3 Kaplan-Meier analysis of cumulative incidence of chronic asthma. Caesarian section vs no caesarean $\operatorname{section}(A) p<0.001,(B) p=0.12$, (C) $p=0.007$, (D) $p=0.002$ (log rank test).

group. In this study population, at the age of 8 years asthma was highly associated with the presence of specific IgE (OR 3.69; 95\% CI 2.69 to 5.06 ) (data not shown).

\section{DISCUSSION}

This study has shown that children born by caesarean section have a higher risk of asthma than children born by vaginal delivery. This risk increases with the number of allergic parents. Only among children with non-allergic parents does delivery by caesarean section increase the risk of sensitisation to common allergens at the age of 8 years.

Previous studies on the association between delivery by caesarean section and asthma reported controversial results. Maitra et $a l^{19}$ did not find a relation between caesarean section and asthma. They also considered the previous published studies and concluded that caesarean section significantly increased the risk of having asthma with a combined odds ratio of 1.25 (95\% CI 1.10 to 1.42 ). However, these studies varied in definition of asthma and in age of children at the time of diagnosis.

The strengths of this study were the sample size, the prospective data collection of outcomes which avoids recall bias, and the definition of asthma based on symptoms and prescription of inhaled steroids. Wheeze is a very common symptom in childhood and, before the age of 6 years, the majority of children with wheeze were shown to have transient forms. ${ }^{28}$ However, wheeze is also a common symptom of asthma so it was included in the definition, and we investigated only children with persisting asthma until the age of 8 years. A definition based on doctor diagnosis probably leads to an underestimation of the prevalence of asthma. Since the parents reported symptoms in the questionnaires, some children were probably misclassified as having asthma. On the other hand, this misclassification is unlikely to be related to the mode of delivery and, despite the fact that this could lead to an underestimation of the association by dilution effect, we found a positive association between caesarean section and asthma. Moreover, we performed the analysis with doctor-diagnosed asthma as the outcome and observed a similar tendency of an association with caesarean section. Selection bias is unlikely in this study since the excluded and included children did not differ significantly. Moreover, loss to follow-up and missing data were independent of the mode of delivery, and the caesarean section rate was the same among the excluded and included children. Socioeconomic status may be considered as a confounder. However, in the Netherlands the prevalence of caesarean section is low and elective caesarean section is rare. The PIAMA study reflects well the national situation. We therefore did not expect an association between caesarean section and socioeconomic status. Moreover, the analyses did not show an association between parental education or occupation and caesarean section and asthma. Pregnancy complications are unlikely to act as a confounder. However, to investigate the effect of these complications we used intrauterine growth retardation, Apgar score and breathing problems after delivery as indicators in our model. This did not change our results.

Several studies have shown that parental allergy is a strong predictor for asthma in childhood. ${ }^{25}{ }^{26}$ Litonjua et al showed that maternal asthma was more strongly associated with asthma in childhood than paternal asthma. ${ }^{29}$ Parental allergic status could have an influence on the association between caesarean section and asthma. One study observed an increased risk of food allergy in children born by caesarean section, especially among children with an allergic mother. ${ }^{2}$ Although this study only evaluated the influence of maternal allergy, the results suggest that parental allergic status might interact with environmental factors to determine the risk of allergic diseases in children. We observed that both maternal and paternal allergy influenced the strength of the association between caesarean section and asthma. The risk of having asthma was even higher in children with two allergic parents. 
Our findings that children born by caesarean section had an increased risk of asthma with a different magnitude depending on the parental history of allergy suggest a strong interaction between genetic factors and the mode of delivery on the development of asthma. Hoffjan et al ${ }^{30}$ studied the hypothesis that early life exposures (day care attendance, the presence of older siblings in the household and viral infections in the first year of life) interact with a child's genotype to influence the development of allergic diseases and asthma and founded significant gene-environment interactions. The presence of complex interactions between genetic factors and exposures could explain the inconsistent results of studies on the association between exposure factors (such as the mode of delivery) and asthma.

The mechanism by which caesarean section could be a risk factor for asthma later in life is not clear. Gronlund et al showed that children born by caesarean section had a delayed and different intestinal colonisation. ${ }^{10}{ }^{11}$ According to the hygiene hypothesis, this could influence the persistence of the fetal Th2 response during early childhood. ${ }^{9}$ An association between asthma and specific IgE to both inhalant and food allergens has been shown ${ }^{31}$ and, moreover, sensitisation to inhalant allergens is highly predictive for asthma. ${ }^{33}{ }^{34}$ We observed similar results with a significant association between asthma and specific IgE at the age of 8 years. The risk of sensitisation to a specific allergen was also higher in children born by caesarean section than in children born by vaginal delivery, but only among children with non-allergic parents. One reason for this might be that the level of specific IgE was already high in children with allergic parents because of the strong genetic influence and therefore we did not observe the influence of caesarean section on allergic sensitisation.

We conclude that delivery by caesarean section is a risk factor for asthma in childhood and that this association is stronger in children with allergic parents. In children with non-allergic parents, those born by caesarean section also have an increased risk of sensitisation to common allergens compared with children born by vaginal delivery. Our results emphasise the importance of gene-environment interactions on the development of asthma in children. The increased rate of caesarean section is partly due to maternal demand without medical reason. In this situation the mother should be informed of the risk of asthma for her child, especially when the parents have a history of allergy or asthma.

Funding: This work was supported by the Netherlands Organisation for Health Research and Development, the Netherlands Asthma Foundation and the Netherlands Ministry of Health, Welfare and Sport.

Competing interests: None.

Ethics approval: The study protocol was approved by the medical ethics committees of the participating institutes and all parents gave written informed consent.

\section{REFERENCES}

1. Annesi-Maesano I, Moreau D, Strachan D. In utero and perinatal complications preceding asthma. Allergy 2001;56:491-7.

2. Eggesbo $\mathbf{M}$, Botten $\mathrm{G}$, Stigum $\mathrm{H}$, et al. Is delivery by cesarean section a risk factor for food allergy? J Allergy Clin Immunol 2003;112:420-6.
3. Beasley R, Crane J, Lai CK, et al. Prevalence and etiology of asthma. J Allergy Clin Immunol 2000;105(2 Pt 2):S466-72.

4. Magnus $\mathbf{P}$, Jaakkola JJ. Secular trend in the occurrence of asthma among children and young adults: critical appraisal of repeated cross sectional surveys. BMJ 1997;314:1795-9.

5. Hamilton BE, Martin JA, Sutton PD. Births: preliminary data for 2003. Nat/ Vital Stat Rep 2004:53:1-17.

6. Arias E, MacDorman MF, Strobino DM, et al. Annual summary of vital statistics2002. Pediatrics 2003;112(6 Pt 1):1215-30.

7. Belizan JM, Althabe F, Barros FC, et al. Rates and implications of caesarean sections in Latin America: ecological study. BMJ 1999;319:1397-400.

8. Kwee A, Elferink-Stinkens PM, Reuwer PJ, et al. Trends in obstetric interventions in the Dutch obstetrical care system in the period 1993-2002. Eur J Obstet Gynecol Reprod Biol 2007;132:70-5.

9. Strachan DP. Hay fever, hygiene, and household size. BMJ 1989:299:1259-60.

10. Bennet R, Nord CE. Development of the faecal anaerobic microflora after caesarean section and treatment with antibiotics in newborn infants. Infection 1987;15:332-6.

11. Gronlund MM, Lehtonen OP, Eerola E, et al. Fecal microflora in healthy infants born by different methods of delivery: permanent changes in intestinal flora after cesarean delivery. J Pediatr Gastroenterol Nutr 1999;28:19-25.

12. Gronlund MM, Arvilommi $\mathrm{H}$, Kero $\mathrm{P}$, et al. Importance of intestinal colonisation in the maturation of humoral immunity in early infancy: a prospective follow up study of healthy infants aged 0-6 months. Arch Dis Child Fetal Neonatal Ed 2000;83:F186-92.

13. Kero J, Gissler M, Gronlund MM, et al. Mode of delivery and asthma -- is there a connection? Pediatr Res 2002;52:6-11.

14. Xu B, Pekkanen J, Hartikainen AL, et al. Caesarean section and risk of asthma and allergy in adulthood. J Allergy Clin Immunol 2001;107:732-3.

15. Xu B, Pekkanen J, Jarvelin MR. Obstetric complications and asthma in childhood. J Asthma 2000;37:589-94.

16. Renz-Polster H, David MR, Buist AS, et al. Caesarean section delivery and the risk of allergic disorders in childhood. Clin Exp Allergy 2005;35:1466-72.

17. Negele K, Heinrich J, Borte M, et al. Mode of delivery and development of atopic disease during the first 2 years of life. Pediatr Allergy Immunol 2004;15:48-54.

18. Salam MT, Margolis HG, McConnell R, et al. Mode of delivery is associated with asthma and allergy occurrences in children. Ann Epidemiol 2006;16:341-6.

19. Maitra A, Sherriff A, Strachan D, et al. Mode of delivery is not associated with asthma or atopy in childhood. Clin Exp Allergy 2004;34:1349-55.

20. McKeever TM, Lewis SA, Smith C, et al. Mode of delivery and risk of developing allergic disease. J Allergy Clin Immunol 2002;109:800-2.

21. Juhn YJ, Weaver A, Katusic S, et al. Mode of delivery at birth and development of asthma: a population-based cohort study. J Allergy Clin Immunol 2005;116:510-6.

22. Bager $\mathbf{P}$, Melbye $M$, Rostgaard $K$, et al. Mode of delivery and risk of allergic rhinitis and asthma. J Allergy Clin Immunol 2003;111:51-6.

23. Nafstad P, Magnus P, Jaakkola JJ. Risk of childhood asthma and allergic rhinitis in relation to pregnancy complications. J Allergy Clin Immunol 2000;106:867-73.

24. Thavagnanam S, Fleming J, Bromley A, et al. A meta-analysis of the association between Caesarean section and childhood asthma. Clin Exp Allergy 2008;38:629-33.

25. Young S, Le Souef PN, Geelhoed GC, et al. The influence of a family history of asthma and parental smoking on airway responsiveness in early infancy. N Eng/ J Med 1991;324:1168-73.

26. Sears MR, Holdaway MD, Flannery EM, et al. Parental and neonatal risk factors for atopy, airway hyper-responsiveness, and asthma. Arch Dis Child 1996;75:392-8.

27. Brunekreef B, Smit J, de Jongste J, et al. The prevention and incidence of asthma and mite allergy (PIAMA) birth cohort study: design and first results. Pediatr Allergy Immunol 2002;13(Suppl 15):55-60.

28. Martinez FD, Wright AL, Taussig LM, et al. Asthma and wheezing in the first six years of life. The Group Health Medical Associates. N Engl J Med 1995;332:133-8.

29. Litonjua AA, Carey VJ, Burge HA, et al. Parental history and the risk for childhood asthma. Does mother confer more risk than father? Am J Respir Crit Care Med 1998;158:176-81

30. Hoffjan S, Nicolae D, Ostrovnaya I, et al. Gene-environment interaction effects on the development of immune responses in the 1st year of life. Am J Hum Genet 2005; 76:696-704

31. Burrows B, Martinez FD, Halonen $\mathrm{M}$, et al. Association of asthma with serum IgE levels and skin-test reactivity to allergens. N Engl J Med 1989;320:271-7.

32. Wever-Hess J, Kouwenberg JM, Duiverman EJ, et al. Prognostic characteristics of asthma diagnosis in early childhood in clinical practice. Acta Paediatr 1999:88:827-34.

33. Kotaniemi-Syrjanen A, Reijonen TM, Romppanen J, et al. Allergen-specific immunoglobulin $\mathrm{E}$ antibodies in wheezing infants: the risk for asthma in later childhood. Pediatrics 2003;111:e255-61.

34. Eysink PE, ter Riet G, Aalberse RC, et al. Accuracy of specific lgE in the prediction of asthma: development of a scoring formula for general practice. Br J Gen Pract 2005;55:125-31. 